\title{
PENGARUH KEPEMIMPINAN TRANSFORMASIONAL DAN SELF EFFICACY TERHADAP MOTIVASI GURU SEKOLAH DASAR NEGERI DI KECAMATAN KRAMAT JATI, JAKARTA TIMUR
}

\author{
Dwi Endah Wahyuningsih. ${ }^{1}$
}

\begin{abstract}
The purpose of this research is to determine the effect of transformational leadership and self-efficacy on motivation the teacher state primary school the district of Kramat Jati East Jakarta. The research methodology was survey which were selected by simple random sampling technique. Analysis and interpretation of the data indicate that (1) transformasional leadership has a positive direct effect in motivation, (2) self-efficacy has a positive direct effect in motivation, (3) transformational leadeship has a positive direct effect in self-efficacy.
\end{abstract}

Keywords: transformational leadership, self-efficacy, motivation.

\section{PENDAHULUAN}

Pendidikan sebagai salah satu upaya untuk membangun dan meningkatkan mutu sumber daya manusia menuju era globalisasi yang penuh dengan tantangan harus diarahkan menuju pendidikan yang visioner yaitu memiliki misi yang jelas sehingga menghasilkan keluaran yang bermutu. Oleh karena itu pendidikan tidak dapat diabaikan begitu saja, terutama dalam memasuki era persaingan yang semakin ketat tajam dan berat pada abad millennium ini. Pendidikan di Indonesia diharapkan dapat mempersiapkan peserta didik menjadi warga Negara yang memiliki komitmen kuat dan konsisten untuk membangun dan mempertahankan Negara Kesatuan Republik Indonesia. Penyelenggaraan pendidikan yang tertata secara baik dan sistematis dapat menjadi suatu sumbangan besar bagi kehidupan masyarakat dan bangsa.

Tanggung jawab dalam mendidik dan membentuk generasi yang berkualitas sepenuhnya berada pada pundak tenaga pendidik, yang lebih di kenal dengan profesi guru. Menanamkan nilai-nilai dan memberikan penge-tahuan pada individu lain bukan merupakan hal yang mudah untuk dilakukan bahkan bagi seseorang yang telah berpengalaman sebagai guru selama bertahun-tahun. Dalam proses pendidikan di sekolah, guru memegang tugas ganda yaitu sebagai pengajar dan pendidik. Sebagai pengajar guru bertugas menuangkan sejumlah bahan pelajaran ke dalam otak anak didik, sedangkan sebagai pendidik guru bertugas membimbing dan membina anak didik agar menjadi manusia susila yang cakap, aktif, kreatif, dan mandiri.

Kasudin Kota Administrasi Jakarta Timur Didi Sugandi, mengatakan semua guru sudah harus dapat memanfaatkan teknologi dalam pembelajaran seperti menggunakan PowerPoint dalam menyampaikan materi di dalam kelas, untuk itu guru harus terus meningkatkan ketrampilan dan kompetensinya, agar tidak tertinggal dengan kemajuan teknologi dan memotivasi guru dalam mengajar Guru yang menguasai materi, metode, disertai dengan menggunakan media yang tepat akan memiliki rasa percaya diri yang lebih tinggi dibandingkan dengan guru yang tidak menguasai, dan akan lebih bertanggungjawab dalam menjalankan tugasnya. Pemerintah provinsi DKI Jakarta sudah memperhatikan kesejahteraan guru dengan memberi TKD (Tunjangan Kinerja Daerah) yang cukup besar, untuk meningkatkan

1 Guru SD Negeri di Kecamatan Kramat Jati. 
pelayanan, dan kinerja guru, karena itu guru DKI harus bersyukur, karena guru-guru daerah lain di Indonesia belum mendapat tunjangan sebesar yang diberikan pemprov DKI.

Dalam PP No. 53/2010 tentang Disiplin PNS, PNS yang terlambat datang ke kantor, pulang lebih cepat dan alpa (tanpa keterangan), akan dihitung secara kumulatif selama satu tahun dimana jika dalam satu tahun jumlah kumulatifnya mencapai 46 hari maka bisa berakibatkan pada pemecatan PNS yang bersangkutan. Kemudian berdasarkan Pergub DKI No.38/2011, PNS yang tidak masuk, terlambat datang dan pulang cepat, maka akan dipotong TKD secara otomatis seperti pemotongan TKD 5 persen jika alpa dan pemotongan sebanyak 2 persen bagi izin. Dari data di atas dapat terlihat masih ada PNS ataupun guru yang tidak atau kurang bertanggungjawab pada tugasnya. Tanggung jawab guru bukan sekedar tanggung jawab biasa tetapi tugas yang harus dipertanggung jawabkan kelak, dan lebih tepat disebut tanggung gugat. Pada dasarnya tingkat tanggung gugat guru dipengaruhi oleh faktor dari dalam guru itu sendiri yaitu keyakinan diri guru untuk dapat mengerjakan tugasnya dengan baik. Sedangkan faktor luar yang diprediksi berpengaruh terhadap tanggung gugat seorang guru yaitu kepemimpinan kepala sekolah, karena kepala sekolah merupakan pemimpin guru di sekolah.

Untuk menciptakan budaya organisasi yang kuat dan motivasi yang tinggi sekolah harus memiliki keunggulan kompetitif (Competitive Advantage) agar dapat memenangkan persaingan, minimal untuk mempertahankan sekolah. Menurut Wakil Menteri Pendidikan Nasional Fasli Jalal, "Kemendiknas akan mendorong profesionalitas guru dengan pertemuan periodik di Kelompok Kerja Guru (KKG) dan Musyawarah Guru Mata Pelajaran (MGMP)." Sejalan dengan Fasli Jalal, Ketua pengurus besar Persatuan Guru Republik Indonesia (PGRI), Unifah Rosyidi mengingatkan "perlunya pengawasan kinerja guru karena peningkatan mutu dan profesional guru bisa dilakukan oleh Kepala Sekolah dengan mendorong guru untuk aktif dalam kegiatan di sekolah dan di MGMP". Uraian di atas menunjukkan bahwa kepemimpinan kepala sekolah dan self-efficacy guru merupakan faktor yang cukup menentukan akuntabilitas (tanggung gugat) guru terhadap tugasnya. Sehingga dapat diduga bahwa masih rendahnya tanggung gugat guru pada tugasnya disebabkan oleh kepemimpinan kepala sekolah yang kurang kuat dan self-efficacy guru yang rendah terhadap pekerjaannya.

Bertitik tolak dari keadaan di atas, maka peneliti memandang perlu adanya penelitian yang mengungkapkan pengaruh kepemimpinaan transformasional dan selfefficacy terhadap motivasi. Peneliti akan melakukan penelitian dengan judul "pengaruh kepemimpinaan transformasional dan self-efficacy terhadap motivasi guru SD Negeri Di Kecamatan Kramat Jati, Jakarta Timur.

\section{Motivasi}

Jason A Colquitt, Jeffery A. Lepine, Michael J. Wesson (2015:164) mendefinisikan motivasi, "motivation is defined as a set of energetic forces that originates both within and outside an employee, initiates work related effort and determine its direction, intensity and persistence". Motivasi didefinisikan sebagai seperangkat kekuatan energik yang berasal baik di dalam maupun dariluar karyawan, memulai usaha yang berhubungan dengan pekerjaan dan menentukan arah, intensitas dan ketekunan. Senada dengan Gareth R. Jones, Jennifer M. George (2014:406), "Motivation may be defined as psychological forces that 
determine the direction of a person's behavior in a organization, a person's level off effort and person's level or persistence in the face of obstacles". Motivasi dapat didefinisikan sebagai kekuatan psikologis yang menentukan arah perilaku seseorang dalam organisasi, tingkat usaha paling rendah seseorang atau kegigihan dalam menghadapi rintangan.

Selanjutnya Fred Luthans (2011:157) mengatakan, "motivation is a process that starts with physiological or psychological deficiency or need that activates a behavior or a drive that is aimed at a goal or incentive". Motivasi adalah proses yang dimulai dengan defisiensi fisiologis atau psikologis atau kebutuhan yang memicu perilaku yang ditujukan untuk tujuan atau insentif. Hal senada John Ivancevich, Robert Konopaske (2013:54) mengatakan, "motivation is the set off attitudes predispose a person to act a specific goal-directed way". Motivasi adalah sikap yang cenderung mempengaruhi seseorang untuk bertindak dengan cara yang diarahkan untuk tujuan tertentu. Menurut Robert Kreitner, Angelo Kinicki (2010:212) motivasi adalah, "motivation represents those psychological processes that cause the arousal, direction and persistence of voluntary actions that are goal directed". Motivasi merupakan proses-proses psikologis yang menyebabkan gairah, arah dan ketekunan dari tindakan sukarela yang tujuannya diarahkan.

Mitchell T.R dalam Stephen P. Robbins, Timothy A. Judge (2013:238) mendefinisikan motivasi adalah, "motivation as the processes that account for an individual's intensity, direction and persistence of effort toward attaining a goal". Motivasi adalah proses yang mengukur intensitas individu, arah dan kegigihan usaha seseorang untuk menuju sasaran yang telah ditetapkan. Menurut Thomas S. Bateman, Scoot A. Snell (2015:440) motivasi adalah, "motivation refers to forces that energize, direct and sustain a person's efforts. All behavior, except involuntary reflexes such as eye blinks (which have little to do with management)". Motivasi mengacu pada kekuatan yang memberikan energi, langsung dan mempertahankan upaya seseorang. semua perilaku, kecuali refleks yang disengaja seperti berkedip mata (yang tidak ada hubungannya dengan manajemen).

Dari pandangan beberapa teori dan deskripsi konsep di atas, maka dapat disintesiskan motivasi adalah dorongan yang memiliki kekuatan psikologis dari diri seseorang untuk melaksanakan pekerjaan mengarah pada perilaku, prakarsa, tanggung jawab dan kemampuan dengan indikator; berusaha unggul dalam bekerja, rasional dalam melaksanakan tugas dan dorongan berprestasi dan aktualisasi diri.

\section{Kepemimpinan Transformasional}

Kata transformasional berasal dari kata to transform yang bermakna mentransformasikan atau mengubah sesuatu menjadi bentuk lain yang lain yang berbeda. Misalnya, mentransformasikan visi menjadi realita, potensi menjadi energi nyata, motif berprestasi menjadi prestasi nyata. Ide teori kepemimpinan transformasional (transformational leadership theory) diawali oleh James McGregor Burns (1979) dalam bukunya yang mendapat Pulitzer Price dan National Book Award yang berjudul Leadership. Dalam buku ini Burns menggunakan istilah mentransformasi kepemimpinan (transforming leadership) dimana yang ditransformasikan adalah kepemimpinannya dari pemimpin ke pengikut. Ilmuwan politik James McGregor Burns pertama kali menggunakan istilah "kepemimpinan transformasional" tahun 1978 ketika ia sedang belajar di US. Burns menemukan gaya kepemimpinan yang jarang dan kontras dengan kepemimpinan transaksional.

John R. Schermerhorn, JR, Richard N. Osborn, Mary Uhl-Bien, James G. Hunt (2012:310) mendefinisikan kepemimpinan transformasional sebagai berikut, "transformational leadership occurs when leader broadens and elevates followers interests and 
stir followers to look beyond their own interest to the good of other". Kepemimpinan transformasional terjadi ketika pemimpin memperluas dan meningkatkan pengikut untuk kepentingan dan pengikut untuk melihat dan melampaui kepentingan mereka sendiri dan untuk kebaikannya yang lain. Menurut Richard L. Daft (2015:360), "transformational leadership is characterized by the ability to bring about significant change in both followers and the Organization. Transformational leaders have the ability to lead changes in an organization's vision, strategy and culture as well as promote innovation in products and Technologies". Kepemimpinan transformasional ditandai dengan kemampuan untuk membawa perubahan yang signifikan di kedua pengikut dan Organisasi. Pemimpin transformasional memiliki kemampuan untuk memimpin perubahan dalam visi, strategi dan budaya organisasi serta mempromosikan inovasi dalam produk dan teknologi.

Dari uraian di atas dapat disintesiskan kepemimpinan transformasional adalah perilaku seorang pemimpin yang bekerja dengan orang lain untuk memberdayakan secara optimal sumber daya organisasi (fasilitas, dana, faktor-faktor eksternal organisasi, sumber daya manusia) dalam rangka mencapai tujuan yang bermakna sesuai dengan target capaian yang telah ditetapkan. Dengan indikator: pengaruh individu, menginspirasi, stimulus intelektual dan pertimbangan individu.

\section{Self-Efficacy}

Self-efficacy merupakan suatu konsep yang diturunkan dari teori kognitif social (social cognitive theory) yang pertama kali dikemukakan oleh bandura. Teori ini bertindak sebagai kerangka konseptual dan awal dari teori self-efficacy. Menurut John W. Slocum, JR, Don Hellriegel (2011:151), "self-efficacy is the individuals estimate of his or her own ability to perform a specific task in a particular situation". Self-efficacy adalah individu memperkirakan kemampuan diri sendiri atau untuk melakukan tugas tertentu dalam situasi tertentu. James L. Gibson, James H. Donnelly, Jr, John M. Ivancevich, Robert Konopaske (2012:113) mengungkapkan bahwa, "the belief that one can perform adequately in a situation.self-efficacy has three dimensions : magnitude, strength and generality". Keyakinan bahwa seseorang dapat melakukan memadai dalam keberhasilan situation.self memiliki tiga dimensi: besarnya, kekuatan dan umum

Sementara itu Steven L. McShane, Mary Ann Von Glinow (2010:45), "self-efficacy a person belief that he or she has the ability motivation, correct role perceptions and favorable situation to complete a task successfully". Efikasi diri seseorang keyakinan bahwa ia memiliki motivasi kemampuan, persepsi peran yang benar dan situasi yang menguntungkan untuk menyelesaikan tugas dengan sukses. Hal berbeda yang di ungkapkan oleh Bandura yang dikutip oleh Fred Luthans (2011:203) mengemukakan, "the formal definition of self-efficacy that is usually used in bandura's early statement of personal judgement or belief of how well one can execute courses of action required to deal with prospective situations". Definisi formal dari self-efficacy yang biasanya digunakan dalam pernyataan awal Bandura penilaian pribadi atau keyakinan dari seberapa baik seseorang dapat melaksanakan program tindakan yang diperlukan untuk menangani situasi calon.

Selanjutnya Stajkovic yang di kutip oleh Fred Luthans (2010:203) menyatakan bahwa, "self-efficacy revers to an individual's conviction (or convidence) about his or her abilities to mobilize the motivation, cognitif resources of action needed to successfully execute as specific task within a given context". Pengertian tersebut menjelaskan bahwa self-efficacy mengacu pada keyakinan individu mengenai kemampuannya untuk memobilisasi motivasi, 
sumber daya kognitif, dan tindakan yang diperlukan agar dapat berhasil melaksanakan tugas dalam konteks tertentu.

Dengan demikian, dapat disintesiskan bahwa self-efficacy adalah keyakinan seseorang terhadap kekuatan diri dalam mengerjakan suatu tugas dengan indikator: melaksanakan tugas, mengatasi masalah dan menyelesaikan tugas.

\section{METODE PENELITIAN}

Penelitian ini menggunakan metode survey dengan teknik analisis jalur (path analys) Data penelitian ini dikumpulkan dengan cara memilih sampel dalam populasi. Populasi terjangkau dalam penelitian ini adalah seluruh guru sekolah dasar negeri di Kecamatan Kramat Jati, Jakarta Timur yang berjumlah 871 guru. Dan perhitungan dengan menggunakan slovin, maka di peroleh jumlah sampel sebanyak 90 guru yang dijadikan sampel frame dalam penelitian ini. Teknik pengumpulan data yang digunakan untuk penelitian ini adalah kuesioner. Selanjutnya dilakukan uji coba intrumen untuk menentukan butir-butir instrumen yang valid dan reliabel. Teknik analisis data dilakukan dengan statistika deskriptif dan statistika inferensial dengan terlebih dahulu melakukan uji prasyarat analisis yaitu normalitas populasi dan analisis regresi.

\section{HASIL PENELITIAN DAN PEMBAHASAN}

\section{Pengaruh kepemimpinan transformasional terhadap motivasi.}

Dari hasil pengujian hipotesis pertama dapat disimpulkan bahwa terdapat pengaruh langsung positif kepemimpinan transformasional terhadap motivasi dengan nilai koefisien korelasi sebesar 0,451 dan nilai koefisien jalur sebesar 0,339. Ini memberikan makna kepemimpinan transformasional berpengaruh langsung terhadap motivasi.

Hasil penelitian ini senada dengan pendapat beberapa ahli di antaranya adalah Gary Yulk (2013:313) dalam bukunya leadership in organization 8 edition, "with transformational leadership, the followers feel trust, admiration, loyalty and respect toward the leader and they are motivated to do more than they originally expected to do". Kepemimpinaan transformasional merujuk kepada nilai-nilai moral pengikut dalam upaya untuk meningkatkan kesadaran tentang isu-isu etis dan untuk memobiliasasi energy dan sumber daya untuk mereformis lembaga mereka.

Selanjutnya Gary Yukl (2013:313) mengatakan bahwa setiap pemimpin harus bisa, "the leader transforms and motivates followers by (1) making them more aware of the importance of task outcomes, (2) inducing them, to transcend their own self interest for the sake of the organization or team and (3) activating their higher orders needs". Para pemimpin transformasi harus bisa memotivasi pengikutnya dengan (1) membuat mereka lebih sadar akan pentingnya hasil tugas, (2) mendorong mereka, melampaui kepentingan diri mereka sendiri demi organisasi atau tim dan (3) mendahulukan perintah pimpinan dari kepentingan pribadi. Selanjutnya menurut Bernard M. Bass didalam bukunya leadership and performance beyond expectations yang di kutip oleh Gary Yulk (2013:313), "according to Bernard M. Bass, transformational leadership increases follower motivation and performance more than transactional leadership, but effective leaders use a combination of both types of leadership". Menurut Bernard M. Bass, kepemimpinan transformasional dapat meningkatkan motivasi bawahan dan dapat meningkatkan kinerja dari karyawan yang di bawah kepemimpinan traksaksional, namun pemimpin yang efektif harus bisa 
menggunakan secara kombinasi dari kedua jenis kepemimpinan tersebut. Gareth R. Jones, Jennifer M. George (2014:406) menjelaskan, "motivation may be defined as psychological forces that determine the direction of a person's behavior in a organization, a person's level off effort and person's level or persistence in the face of obstacles". Motivasi dapat didefinisikan sebagai kekuatan psikologis yang menentukan arah perilaku seseorang dalam organisasi, tingkat usaha paling rendah seseorang atau kegigihan dalam menghadapi rintangan. Selanjutnya Fred Luthans (2011:157) mengatakan, "motivation is a process that starts with physiological or psychological deficiency or need that activates a behavior or a drive that is aimed at a goal or incentive". Motivasi adalah proses yang dimulai dengan defisiensi fisiologis atau psikologis atau kebutuhan yang memicu perilaku yang ditujukan untuk tujuan atau insentif. Hal senada John Ivancevich, Robert Konopaske (2013:54) mengatakan, "motivation is the set off attitudes predispose a person to act a specific goal-directed way". Motivasi adalah sikap yang cenderung mempengaruhi seseorang untuk bertindak dengan cara yang diarahkan untuk tujuan tertentu. Dengan demikian, ketepatan dalam kepemimpinan transformasional, maka akan mengakibatkan peningkatan motivasi seseorang.

\section{Pengaruh self-efficacy terhadap motivasi}

Dari hasil pengujian hipotesis kedua dapat disimpukan bahwa terdapat pengaruh langsung positif self-efficacy terhadap motivasi dengan nilai koefisien korelasi sebesar 0,459 dan nilai koefisien jalur sebesar 0,351. Ini memberikan makna self-efficacy berpengaruh langsung terhadap motivasi.

Hasil penelitian ini senada dengan pendapat beberapa ahli di antaranya adalah James L. Gibson, James H. Donnelly, JR, John M. Ivancevich, Robert Konopaske (2012:113), mengatakan bahwa self-efficacy, "he contends that self-efficacy is a belief that we can perform adequately in a particular situation. People's sense of capability influences their perception, motivation and performance". James L. Gibson, James H. Donnelly, JR, John M. Ivancevich, Robert Konopaske berpendapat bahwa self-efficacy adalah keyakinan bahwa kita dapat melakukan secara memadai dalam situasi tertentu. Perasaan masyarakat tentang kemampuan mempengaruhi persepsi mereka, motivasi dan kinerja.

Steven L. McShane, Mary Ann Von Glinow (2010:45) mengatakan, "self-efficacy a person belief that he or she has the ability motivation, correct role perceptions and favorable situation to complete a task successfully". Efikasi diri seseorang keyakinan bahwa ia memiliki motivasi kemampuan, persepsi peran yang benar dan situasi yang menguntungkan untuk menyelesaikan tugas dengan sukses. Selanjutnya Stajkovic yang di kutip oleh Fred Luthans (2010:235) menyatakan bahwa, "self-efficacy revers to an individual's conviction (or convidence) about his or her abilities to mobilize the motivation, cognitifresources of action needed to successfully execute as specific task within a given context". Pengertian tersebut menjelaskan bahwa self-efficacy mengacu pada keyakinan individu mengenai kemampuannya untuk memobilisasi motivasi, sumber daya kognitif, dan tindakan yang diperlukan agar dapat berhasil melaksanakan tugas dalam konteks tertentu.

John W. Slocum, JR, Don Hellriegel (2011:151) menjelaskan, "self-efficacy is the individuals estimate of his or her own ability to perform a specific task in a particular situation". Self-efficacy adalah individu memperkirakan kemampuan diri sendiri atau untuk melakukan tugas tertentu dalam situasi tertentu. Dengan demikian, peningkatan efikasi diri seseorang akan mengakibatkan peningkatan motivasinya. 


\section{Pengaruh kepemimpinan transformasional terhadap self-efficacy}

Dari hasil pengujian hipotesis ketiga dapat disimpulkan bahwa terdapat pengaruh langsung positif kepemimpinan transformasional terhadap self-efficacy dengan nilai koefisien korelasi sebesar 0,320 dan nilai koefisien jalur sebesar 0,320. Ini memberikan makna kepemimpinan transformasional berpengaruh langsung terhadap self-efficacy.

Hasil penelitian ini senada dengan hasil riset berikut ini, Research yang di lakukan Jyoti Aggarwal and Venkat R. Krishnan dengan judul Impact of Transformational Leadership on Follower's Self-Efficacy: Moderating Role of Follower's Impression Management,"enhancing the belief in the abilities of employees to perform a particular task is the critical role played by a transformational leader subject to impression management strategies used by the employees. The purpose of this paper is to report a study on how self-efficacy of the subordinates is enhanced by their use of impression management strategies on supervisors and the impact of transformational leadership in enhancing subordinate's self-efficacy. The results show positive relationship between transformational leadership and the self-efficacy of the subordinates. Self-focused impression management strategies are positively related to the selfefficacy. Other-focused strategies have positive relationship with transformational leadership. Other-focused and job-focused strategies moderate the relation between transformational leadership and self-efficacy, such that there is a positive relationship between transformational leadership and follower self-efficacy only when followers' use of other-focused and job-focused impression management strategies is high". Hasil menunjukkan Pengaruh yang positif antara kepemimpinan transformasional dan kemajuan self-efficacy. Strategi manajemen berfokus pada diri sendiri kesan positif berkaitan dengan self-efficacy. Selanjutnya John R. Schermerhorn, JR, Richard N. Osborn, Mary Uhl-Bien, James G. Hunt (2012:310) mendefinisikan kepemimpinan transformasional sebagai berikut, "transformational leadership occurs when leader broadens and elevates followers interests and stir followers to look beyond their own interest to the good of other". Kepemimpinan transformasional terjadi ketika pemimpin memperluas dan meningkatkan pengikut untuk kepentingan dan pengikut untuk melihat dan melampaui kepentingan mereka sendiri dan untuk kebaikannya yang lain. Sedangkan Richard L. Daft (2015:360) menjelaskan, "transformational leadership is characterized by the ability to bring about significant change in both followers and the Organization. Transformational leaders have the ability to lead changes in an organization's vision, strategy and culture as well as promote innovation in products and Technologies". Kepemimpinan transformasional ditandai dengan kemampuan untuk membawa perubahan yang signifikan di kedua pengikut dan Organisasi. Pemimpin transformasional memiliki kemampuan untuk memimpin perubahan dalam visi, strategi dan budaya organisasi serta mempromosikan inovasi dalam produk dan teknologi. Berdasarkan uraian di atas ketepatan dalam kepemimpinan transformasional akan mengakibatkan peningakatan self-efficacy seseorang.

\section{PENUTUP}

Kesimpulan: (1) Kepemimpinan transformasional berpengaruh langsung positif terhadap motivasi. Artinya kesesuaian gaya kepemimpinan transformasional dalam memimpin sekolah akan mengakibatkan peningkatan motivasi guru SD Negeri di Kecamatan Kramat Jati, Jakarta Timur. (2) Self-Efficacy berpengaruh langsung positif terhadap kinerja. Artinya keyakian guru dalam menyelesaikan pekerjaannya memiliki pengaruh terhadap peningkatkan motivasi guru SD Negeri di Kecamatan Kramat Jati, Jakarta Timur. (3) Kepemimpinan transformasional berpengaruh langsung positif 
terhadap self-efficacy. Artinya kesesuaian gaya kepala sekolah dalam memimpin sekolah memiliki pengaruh kepada self-efficacy guru SD Negeri di Kecamatan Kramat Jati, Jakarta Timur

Saran: (1) Bagi kepala Dinas Pendidikan Kota Jakarta Timur, untuk membantu meningkatkan kinerja guru dengan memberikan kejelasan tupoksi dalam bentuk peraturan yang di sosialisasikan kepada kepala sekolah dan guru. (2) Bagi kepala sekolah dapat meningkatkan motivasi guru dengan menjadikan diri kepala sekolah sebagai inspiratif guru dalam menjalankan tugasnya, membantu guru ketika menghadapi permasalahan dalam menjalankan tugasnya dan memperhatikan kemampuan setiap individu guru dalam pembagian pekerjaan (3) Bagi peneliti lain, dapat dijadikan bahan rujukan dalam rangka peneliti lebih lanjut terkait dengan kepemimpinan transformasional dan self-efficacy terhadap motivasi.

\section{DAFTAR RUJUKAN}

Colquitt, Jason A., Jeffery A. Lepine, Michael J. Wesson, Organizational Behavior Improving performance and commitment in the workplace 4 edition. New York: Mc Graw Hill, 2015.

Daft, Richard L. the leadership experience 6 edition. USA:Cengage Learning,2015.

George, Jennifer M., Gareth Jones, Understanding and managing organizational behavior. New Jersey: Pearson Education, 6th ed., 2012.

Gibson, James L., John M.Ivancevich, James H. Donnelly jr, Robert Konopaske, Organizations Behavior, Structure, Processes. New York : McGraw-Hill/Irwin Companies Inc, 2012.

Helliegel, Don, John W. Slocumm JR, Organizational behavior 13 edition. USA: South Western Cengange Learning, 2011.

Jones, Gareth R, Jennifer M. George, Contemprary Management Global Edition. New York, Mc Graw Hill, 2014.

Luthans, Fred, Organizational Behaviour an Evidence based approach, 12 Edition New York, Mc Graw Hill, 2011.

Manning, George, Kent Curtis, The art of leadership 5 edition. New York: Mc Graw-Hill, 2015.

McShane and Von Glionw, Organizational Behaviour emerging knowledge and practice for the real world (New York: McGraw Hill, 2010.

Newstrom, John W., Organization Behavior human behavior at work Fourteenth Edition New York: McGraw-Hill/Irwin Companies Inc, 2015.

Richard L. Daft, Leadership Theory and Practice 6 edition. USA:Cengage learning, 2015. 
Robbins, Stephen P., Timothy A. Judge, Organizational Behavior 16 Edition. England: Pearson, 2015.

Yulk, Gary, Leadership in Organizations 8 edition. England: Pearson,2013. 